\title{
Preparation and Characterizations of Iron Oxide Nano Particles Reinforced Polymeric Thin Films
}

\author{
R. Mahendran ${ }^{1 *}$, E. Varadarajan ${ }^{2}$, K. Suresh ${ }^{3}$ and J. Palanivel ${ }^{4}$ \\ ${ }^{1}$ Department of Chemistry, Anjalai Ammal Mahalingam Engineering College, Anna University, Chennai, India.
}

${ }^{2}$ Defense Research and Development Organization, Research \& Innovation Centre, IITM Research Park, Chennai, India.

${ }^{3}$ Department of Physics, Anjalai Ammal Mahalingam Engineering College, Anna University, Chennai, India.

${ }^{4}$ Electronics and Communication Engineering Department, Anjalai Ammal Mahalingam Engineering College, Anna University, Chennai, India.

Received: 22 June, 2017; Accepted: 15 July, 2017; Published: 05 August, 2017

*Corresponding author: Rajagopalan Mahendran, Department of Chemistry, Anjalai Ammal Mahalingam Engineering College, Anna University, Kovilvenni - 614 403, Chennai, India. E-mail: anishmahendran10@gmail.com

\begin{abstract}
The aim of this study is to investigate the influence of Iron oxidenano-particles (IONPs) on the physico-chemical properties of poly(vinyl alcohol) (PVA) - poly(2-acrylamido-2-methyl-1propanesulfonic acid) (PAMPS) polymer matrix. The IONPs were synthesized from ferric chloride using $\mathrm{NaBH}_{4}$ as reducing agent in distilled water, and the IONPs were characterized by FT-IR and TGA. Thinnano-composite films were fabricated by blending IONPs colloidal suspension with PVA / PAMPS solution by Thermally Induced Phase Separation technique. The reinforcement of the IONPs in the PVA / PAMPS matrix was also confirmed by FT-IR and TGA, and water uptake measurements revealed the hydrophilic nature of the IONPs. The cross-sectional and surface morphologies of the films were analyzed by High-Resolution Scanning Electron Microscopy, and the results showed that the surface roughness of the films and size of the IONPs enhanced with respect to their content in the polymer matrix.
\end{abstract}

Keywords: Polyvinyl Alcohol; Nanoparticles; Iron Oxides; Water Uptake; Morphological Studies; Thermal Analysis;

\section{Introduction}

Magnetic nano-particles, which can be stimulated under magnetic field gradients, consist mainly iron, cobalt, nickel and their compounds [1-4]. The magnetic nano-particles have been attracted due to the thermal, magnetic and optical properties [5]. Thus, the particles are being potentially used in photonics, electronics, biomedical, magnetically tunable materials, micro and nanofluidics, magnetic particle imaging, data storage and sensors $[6,7]$. In particular, iron oxide $\left(\mathrm{Fe}_{2} \mathrm{O}_{3}\right)$ nano-particles (IONPs) are widely used such applications due to their biocompatible and biodegradable nature and they can be easily controllable by magnetic field $[8,9]$. Further, the IONPs have very large surfaceto-volume ratio, thus they possess high surface energies [5]. However, they are in powdery form and possess less mechanical stability, protects their practical applications. In order to utilize this precious material practically, it could be blended with polymeric materialsin order to enhance their applications as well as physico-chemical properties of the host polymer $[10,11]$.

Recently, chemically cross-linked poly (vinyl alcohol) and poly (2-acrylamido-2-methyl-1-propanesulfonic acid) (PVA-PAMPS) films are effectively used in the mechanical devices, attributable to their biocompatibility and cost-effectiveness $[12,13]$. Notably, the PVA has been widely utilized in the fabrication of tablet coating, artificial tears, drug delivery and tissue replacement, owing to their specific characteristics of toxicologically safe, high oxygen permeability and biodegradability [14], conversely they possess very less mechanical stability. To overcome this major drawback, it should be chemically cross-linked / blended with other hydrophilic materials to acquire mechanically stable materials. Specifically, the PAMPS, a sulfonic acid acrylic monomer has high proton conductivity and well hydrated due to presence of sulfonic acid groups in its backbone, and they are effectively applied infuel cells, medical devices and actuators [7,15]. In order to improve their mechanical and thermal stabilities of these PVA and PAMPS polymers, they could be blended / chemically crosslinked for obtaining flexible, mechanically and thermally stable material $[12,13]$. Generally, the reinforcement of nano-particles into the polymer matrix enhances the mechanical, dimensional and thermal stabilities of the host polymer matrix. Very recently, Guo et al. [16] fabricated IONPs reinforced PVA composites with superior thermal stability, and the IONPs have robust interaction with the PVA matrices by hydrogen bonding between their hydroxyl groups.

In this study, based on the above merits of IONPs in the polymer matrix, PVA/PAMPS / IONPs nano-composite films were fabricated by Thermally Induced Phase Separation technique. The major function of the IONPs is to enhance the thermomechanical properties, magnetic activity (superparamagtic) and dimensional stabilities of the PVA/PAMPS matrix. The physicothermal properties of the PVA/PAMPS/IONPs films were studied 
by thermo gravimetric analysis (TGA) and water-uptake ratio. The reinforcing effect of the IONPs on the micro structural property of the PVA/PAMPS matrix was extensively investigated by High Resolution-Scanning Electron Microscopy (HR-SEM).

\section{Materials and Methods}

\section{Materials}

PVA (Mw $=61,000)$, PAMPS (Mw $=2,000,000), \mathrm{NaBH}_{4}$ and $\mathrm{FeCl}_{3} \cdot 6 \mathrm{H}_{2} \mathrm{O}$ werepurchased from Sigma Aldrich, India, and used as received. Distilled Water (DW) was used as solvent to prepare the PVA and PAMPS solutions and IONPs suspension.

\section{Synthesis and characterizations of IONPs}

The IONPs $\left(\alpha-\mathrm{Fe}_{2} 0_{3}\right.$, hematite $)$ were synthesized using sodium borohydride as reducing agent [17]. Figure 1 shows the schematic representation of synthesis of the IONPs. Firstly, $\mathrm{FeCl}_{3} \cdot 6 \mathrm{H}_{2} \mathrm{O}(7.5$ g) was dissolved in $100 \mathrm{~mL}$ distilled water and stirred for 4 hrs, and $\mathrm{NaBH}_{4}(1 \mathrm{~g} / 100 \mathrm{~mL})$ solution was added to the ferric chloride solution drop wise for an hour at room temperature. The color of solution changed from yellowish to black color, and the nano-particles dispersion were stirred for additional $10 \mathrm{mins}$, and centrifuged, finally. The IONPs were dried in an oven at $100^{\circ} \mathrm{C}$ for $24 \mathrm{hrs}$, and stored ina desiccator until used, and they were characterized by FT-IR and TGA.
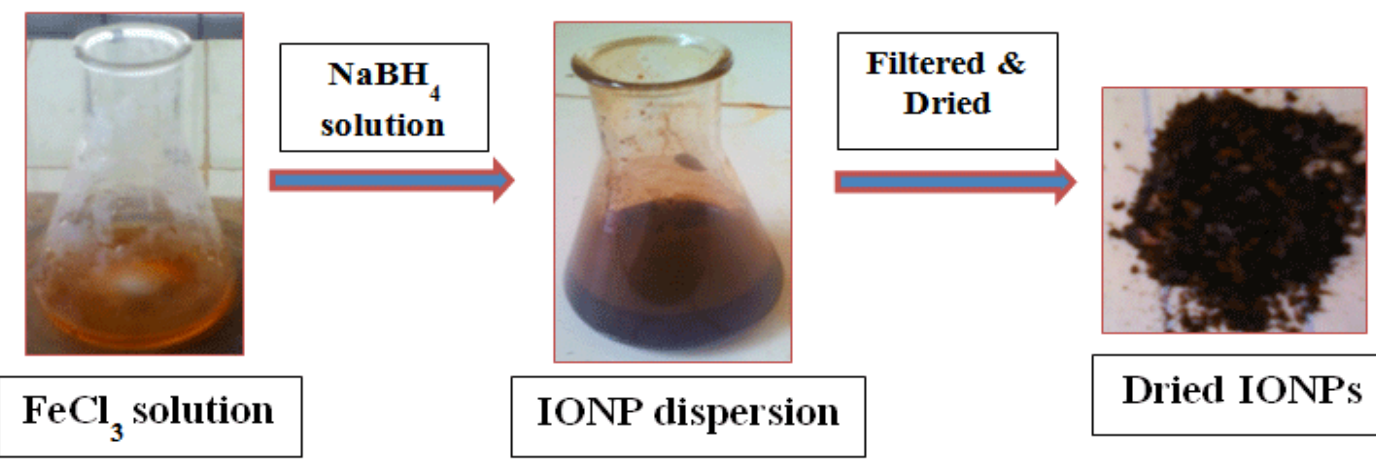

Dried IONPs

Figure 1: Synthesis of $\mathrm{Fe}_{2} \mathrm{O}_{3}$ nano-particles

\section{Preparation of PVA/PAMPS/IONP films}

The PVA/PAMPS/IONP nano-composite films were prepared by Thermally Induced Phase Separation technique [12]. Figure 2 shows the schematic representation of the fabrication of PVA/PAMPS/IONP films. Firstly, the PVA solution(solventdistilled water)was heated to $80^{\circ} \mathrm{C}$ with stirring until to obtain a homogeneous and transparent solution. Additionally, the PAMPS aqueous solution was poured into the PVA solution and stirred for additional 3 hour to attain homogeneity. Furthermore, the IONPs were dispersed in distilled water by ultrasonication for $10 \mathrm{~min}$, and the IONPs dispersion was added to the PVA/ PAMPS mixture, and stirred in a mechanical stirrer for 5 hours to acquirea homogeneous mixture. Then, the solution was poured in a Teflon coated mold and dried in anoven at $90^{\circ} \mathrm{C}$ for 24 hours to evaporate the solvent, utterly. The PVA/PAMPS/IONP films were prepared with various weight ratios, which are shown in the table 1. Furthermore, the PVA/PAMPS film was prepared at the weight ratio of 10:2 in distilled water to compare the influence of the IONPs on the PVA/PAMPS matrix.
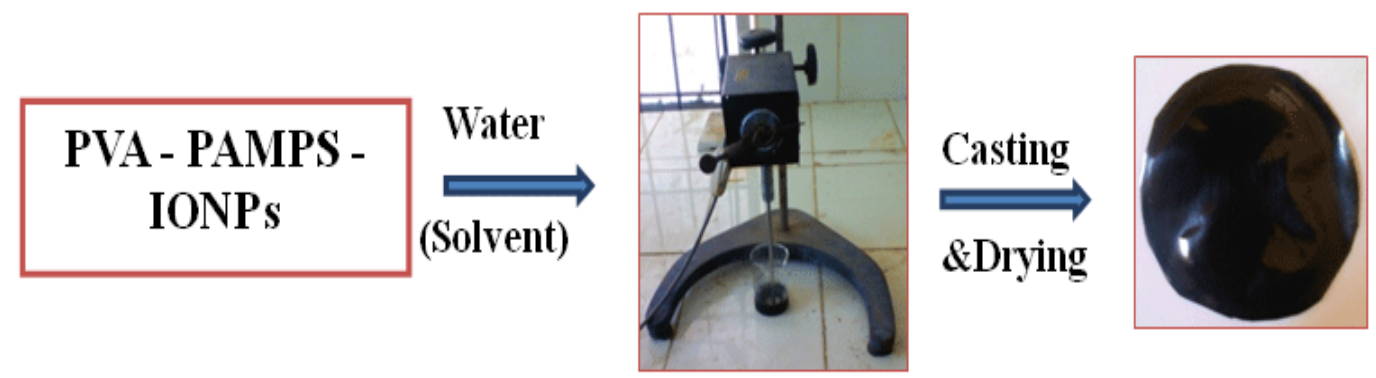

Figure 2: Fabrication of PVA-PAMPS-IONPs nano-composite film 
Table 1: Properties of PVA/PAMPS and PVA/PAMPS/IONP 1-4 films

\begin{tabular}{|c|c|c|c|c|c|}
\hline Film code & $\begin{array}{c}\text { PVA } \\
(\mathrm{wt} \%)\end{array}$ & PAMPS (wt\%) & IONPs (wt\%) & $\begin{array}{c}\text { Water } \\
\text { uptake } \\
(\%)\end{array}$ & $\begin{array}{c}\text { Thickness } \\
(\mu \mathrm{m})\end{array}$ \\
\hline PVA/PAMPS & 10 & 2 & 0 & 66.06 & -- \\
\hline PVA/PAMPS/ IONP -1 & 10 & 2 & 0.5 & 68.58 & 210 \\
\hline PVA/PAMPS/ IONP -2 & 10 & 2 & 1.0 & 70.13 & 234 \\
\hline PVA/PAMPS/ IONP -3 & 10 & 2 & 1.5 & 71.23 & 312 \\
\hline PVA/PAMPS/ IONP -4 & 10 & 2 & 2.0 & 73.83 & 325 \\
\hline
\end{tabular}

\section{Characterizations}

Structural analysis of the PVA, PAMPS, IONPs and PVA/PAMPS/ IONP composite was carried out by Fourier Transform Infrared Spectroscopy (FT-IR,SHIMADZU, IR Prestige-21), and thermal stability of the samples was also analyzed by thermogravimetric analysis (TGA/SDTA851e, Mettler Toledo) under nitrogen atmosphere at heating rate of $10^{\circ} \mathrm{C} / \mathrm{min}$. Further, the hydrophilic nature of the as-prepared films was measured by water uptake measurement by gravimetric method $[18,19]$. The cross-sectional and surface morphologies of the PVA / PAMPS and PVA/PAMPS/ IONP 1-4 thin films were observed by HR-SEM (FEI Quanta, FEG 200). For the analysis, the dried films were fractured, mounted on a stub and sputter-coated with gold.

\section{Results and Discussion}

The thickness of the films increased with respect to the content of IONPs in the PVA/PAMPS matrix, and the films were flexible in nature. The thickness of the PVA/PAMPS/IONP-1, PVA/ PAMPS/IONP -2, PVA/PAMPS/IONP -3 and PVA/PAMPS/IONP -4 were 210, 230, 310 and $325 \mu \mathrm{m}$, respectively. The FT-IR spectra of PVA, PAMPS, IONPs and PVA/PAMPS/IONP composite are shown in the figure 3. In the PVA spectrum, large bands between $3350-3000 \mathrm{~cm}-1$ are linked to the stretching $0-\mathrm{H}$ vibration of intermolecular and intramolecular hydrogen bonds, and the band in the region of $2980-2710 \mathrm{~cm}-1$ refers to the stretching C-H of alkyl groups [12]. In the PAMPS spectrum, the characteristics bands around For convenience, PVA/PAMPS/IONP-1 (0.5 wt\%), PVA/PAMPS/IONP -2 (1.0 wt\%), PVA/PAMPS/IONP -3 (1.5 wt\%) and PVA/PAMPS/IONP -4 (2.0 $\mathrm{wt} \%)$ is denoted as PVA/PAMPS/ IONP 1-4 films.

1556 and $1650 \mathrm{~cm}-1$ were showed the vibrational mode of amide groups, the two sharp peaks at 1039 and $1221 \mathrm{~cm}-1$ were observed for the $\mathrm{S}-\mathrm{O}$ stretching of sulfonate groups, and the band around $3400-3000 \mathrm{~cm}-1$ owing to the $\mathrm{O}-\mathrm{H}$ stretching vibration $[12,13]$. In the IONPs spectrum, the broad band at 3700-3000 $\mathrm{cm}-1$ indicated the stretching vibration mode of surface hydroxyl groups of the pristine IONPs [20]. In the PVA/PAMPS/IONP spectrum, the stretching absorption band attributed to the C-N of PAMPS decreases with more cross-linking, followed by an increased sharp peak due to the $\mathrm{C}=0$ from PAMPS. The broad peak observed around 3500-3000 cm-1 due to the O-H stretching vibration of the PVA, PAMPS and IONPs in the nano-composite films. Hence, the incorporation of IONPs in the polymer matrix was concluded by the FT-IR.

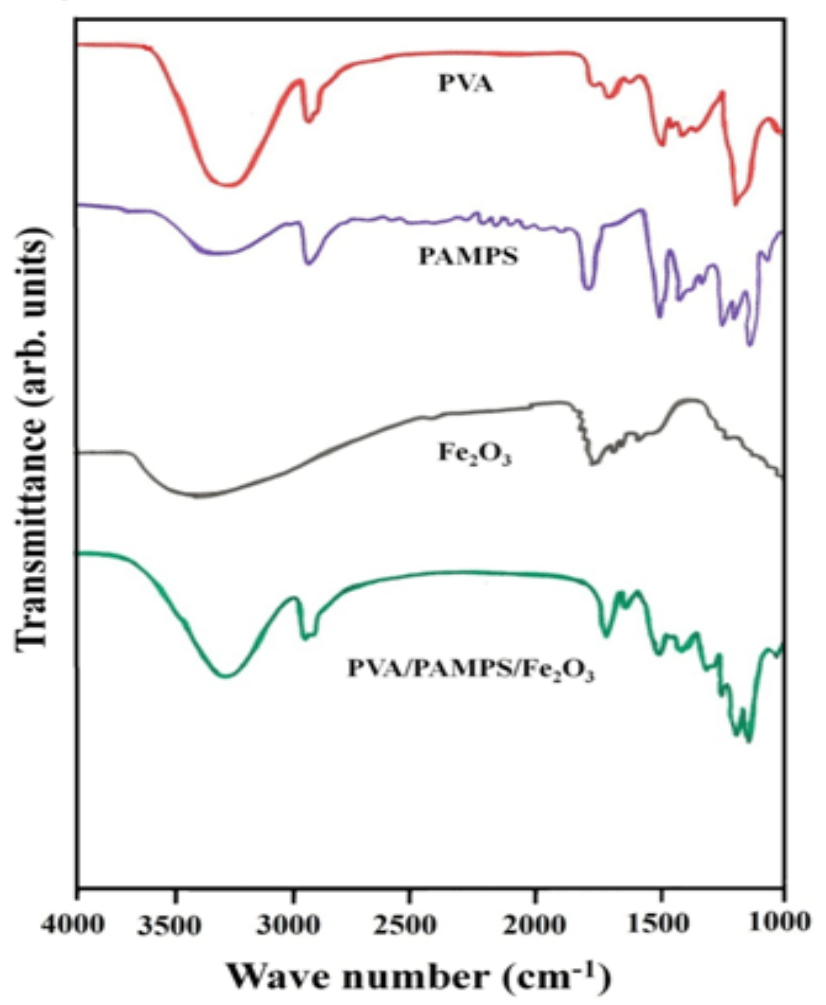

Figure 3: FT-IR spectra of PVA, PAMPS, IONPs and PVA/PAMPS/IONP composite

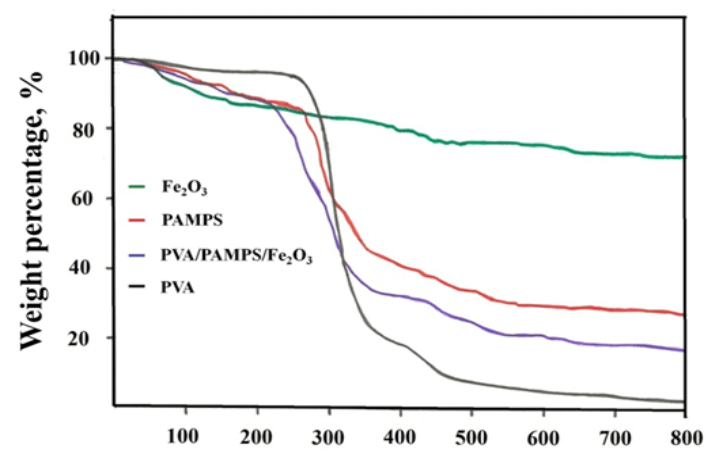

Figure 4:TGA of PVA, PAMPS, IONP and PVA/PAMPS/IONP composite 
Figure 4 shows the Thermo Gravimetric Analysis (TGA) curves of PVA, PAMPS, IONPs and PVA/PAMPS/IONP composite. The mass loss of the PVA occurred in two stages: The first mass loss around $100-150^{\circ} \mathrm{C}$ was attributable to the loss of water molecules and the second mass loss around $250-350^{\circ} \mathrm{C}$ owing to the thermal degradation of the PVA backbone $[12,13]$. In the PAMPS, the decomposition temperature occurred at $100^{\circ} \mathrm{C}$ due to moisture loss, and around $300^{\circ} \mathrm{C}$ was the decomposition of sulfonate and propenyl groups. Finally, $\sim 380-430^{\circ} \mathrm{C}$ was the degradation of the PAMPS backbone [12]. In the IONPs, two major mass losses at about $100^{\circ} \mathrm{C}$ and $200-250^{\circ} \mathrm{C}$ were observed. At $100^{\circ} \mathrm{C}$, it could be attributed to the evaporation of moisture, and the mass of the IONPs becomes gradually decreased until the
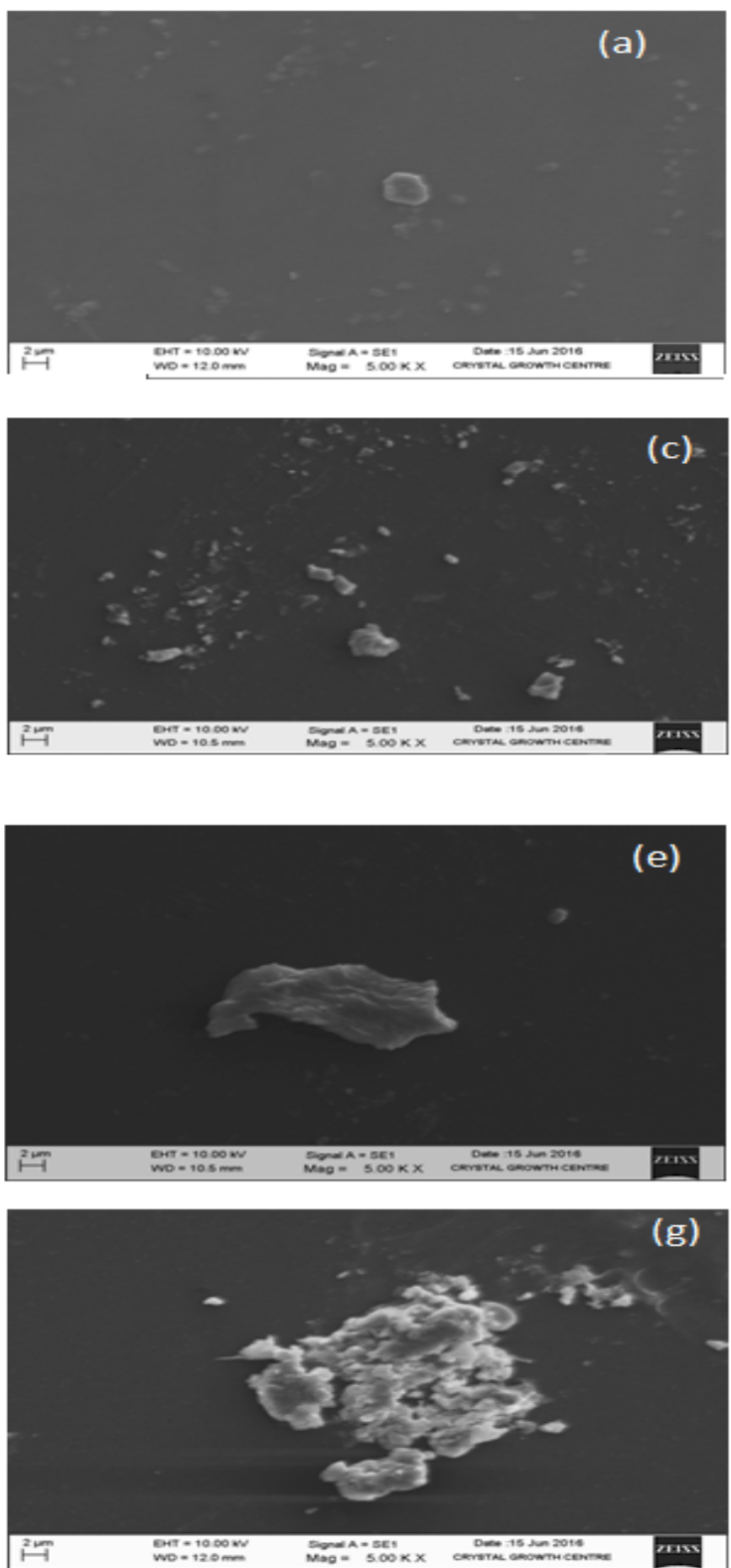

temperature reaches $380^{\circ} \mathrm{C}$. The mass loss around $200-300^{\circ} \mathrm{C}$ correspond to the thermal decomposition of oxygen-containing functional groups from the IONPs [21,22]. In the degradation curve of PVA/PAMPS/IONP composite, minute mass loss at $100^{\circ} \mathrm{C}$ due to moisture content, and the mass of the sample gradually decreased to $600^{\circ} \mathrm{C}$. The mass loss around $170-200^{\circ} \mathrm{C}$,could be attributed to the removal of labile oxygen functional groups from the PVA/PAMPS/IONP nano-composite. The mass loss between $240-400^{\circ} \mathrm{C}$, owing to the decomposition of sulfonic acid groups from the PAMPS, and the mass loss after $400^{\circ} \mathrm{C}$ belongs to the breaking of the polymer backbone.

The addition of IONPs changed the water uptake property of the as prepared nano-composite films, significantly (Table 1)
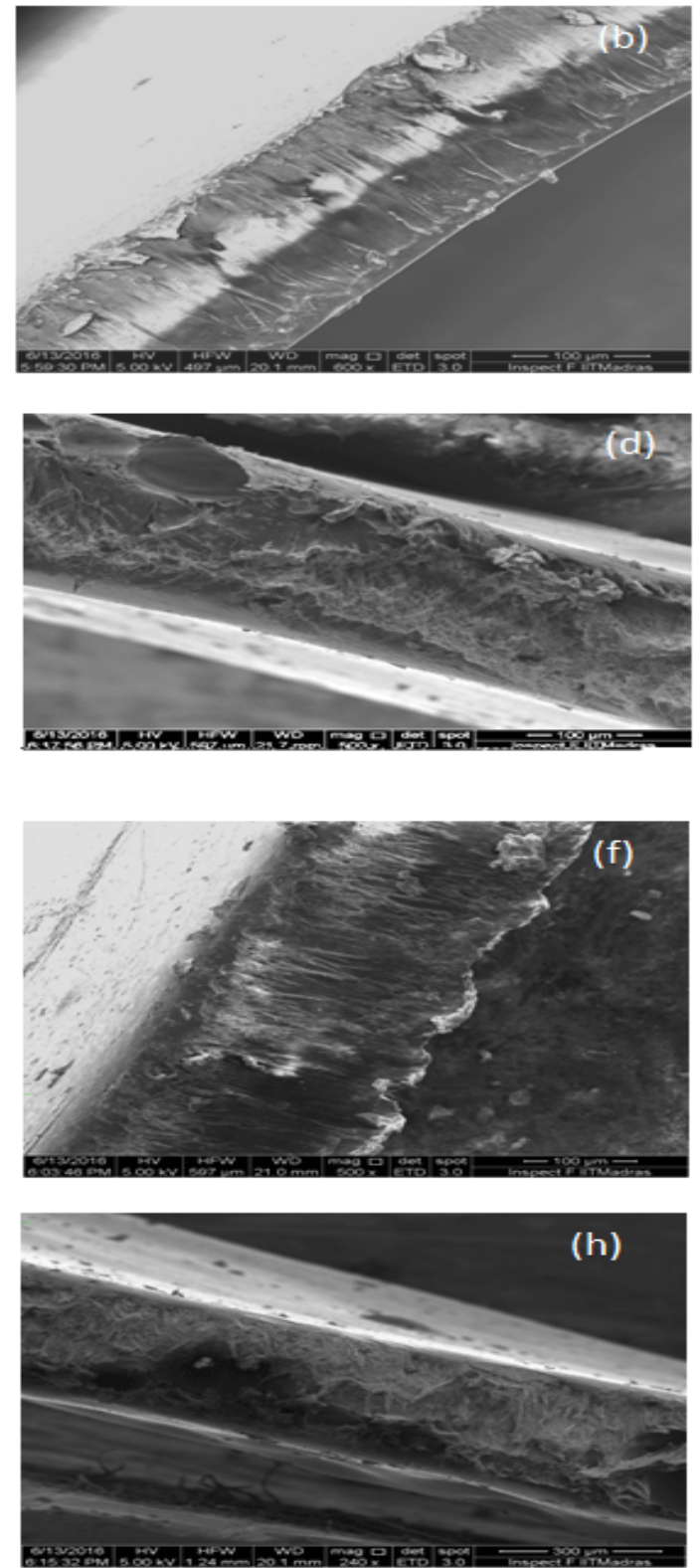

Figure 5: HR-SEM image of PVA/PAMPS/IONP-1 (a and b), PVA/PAMPS/IONP-2 (c and d), PVA/PAMPS/IONP-3 (e and f) and PVA/PAMPS/IONP-4(g and h) films

Citation: Mahendran R, Varadarajan E, et al. (2017) Preparation and Characterizations of Iron Oxide Nano-Particles Reinforced 
$[23,24]$. It can be elucidated by the interaction of the hydrophilic IONPs and the hydrophilic PVA/PAMPS matrix with the water molecules $[12,13]$. The water content of the PVA/PAMPS $(66.06$ \%), PVA/PAMPS/IONP-1 (68.58 \%), PVA/PAMPS/IONP -2 (70.13 $\%)$, PVA/PAMPS/IONP -3 (71.23\%) and PVA/PAMPS/IONP -4 (73.83 \%) were observed. Hence, the incorporation of IONPs enhances the water absorption capacity of the nano-composites with respect to their content in the polymer matrix.

The surface and cross-sectional morphologies of the PVA/ PAMPS/IONP 1-4 films are shown the in figure 5 (a-h). The surface roughness and particle size of the IONPs in the nanocomposite films improved with respect to the concentration $[0.5$ to $2.0 \mathrm{wt} \%$ ) of the IONPs in the polymer matrix of PVA/PAMPS/ IONP 1-4 films, respectively, which was clearly identified from the figure. 5 a, c, e and g, respectively.

\section{Conclusions}

Iron oxide nano-particles reinforced poly (vinyl alcohol) and poly 2-acrylamido-2-methyl-1-propanesulfonic acid based nanocomposite were fabricate dutilizing distilled water as solvent ("Green" route method) by TIPS. The IONPs were effectively synthesized by chemical reduction of $\mathrm{FeCl}_{3} \cdot 6 \mathrm{H}_{2} \mathrm{O}$ using sodium borohydride as reducing agent. The reinforcement of IONPs in the PVA/PAMPS matrix was clearly validated by FT-IR and TGA. Further, the water uptake capacity of the PVA/PAMPS/IONP films increased with respect to the IONPs content, which might be due to the hydrophilic nature of IONPs. The HR-SEM images clearly revealed the agglomeration of IONPs on the surface of the films by increasing their content in the polymer matrix. Thus, the fabricated mechanically and thermally stable PVA/PAMPS/IONPs nano-composite films can be effectively applied in magnetic actuators and sensors, energy harvesters, and spintronic devices, owing to their light weight, hydrophilicity, cost effective and compactness.

\section{Conflict of Interest}

The authors declare that they have no competing interests.

\section{References}

1. Lu AH, Salabas EL, Schuth F. Magnetic Nanoparticles: Synthesis, Protection, Functionalization and Application. Angew Chem Int Ed Engl. 2007;46(8):1222-1244. doi: 10.1002/anie.200602866

2. Arzadeh A, Samiei M, Davaran S. Magnetic nanoparticles: preparation, physical properties, and applications in biomedicine. Nanoscale Res Lett. 2012;7:144-157. doi: 10.1186/1556-276X-7-144

3. Stanicki D, Elst LV, Muller RN. Synthesis and processing of magnetic nanoparticles. Curr Opin Chem Eng. 2015;8:7-14.

4. Sundaresan V, Menon JU, Rahimi M, Nguyen KT, Wadajkar AS. Dual-responsive polymer-coated iron oxide nanoparticles for drug delivery and imaging applications. Int J Pharm. 2014;466(1-2):1-7. doi: 10.1016/j.ijpharm.2014.03.016

5. Tang SCN, Lo IMC. Magnetic nanoparticles: Essential factors for sustainable environmental applications. Water Res. 2013;47(8):2613-2632. doi: 10.1016/j.watres.2013.02.039

6. Saeid Zanganeh, Gregor Hutter, Ryan Spitler, Olga Lenkov, Morteza Mahmoudi, Aubie Shaw, et al. Iron oxide nanoparticles inhibit tumour growth by inducing pro-inflammatory macrophage polarization in tumour tissues. Nat Nanotechnol. 2016;11:986-994. doi: $10.1038 /$ nnano.2016.168

7. Kim SJ, Lee CK, Kim SI. Electrical / pH responsive properties of poly (2-acrylamido-2-methylpropane sulfonic acid) / hyaluronic acid hydrogels. J ApplPolym Sci. 2004;92(3):1731-1736. doi: 10.1002/ app.20133

8. Guskos N, Glenis S, Likodimos V, J. Typek, M. Maryniak, M. Kwiatkowska, et al. Matrix effects on the magnetic properties of $\boldsymbol{\gamma}-\mathrm{Fe}_{2} \mathbf{O}_{3}$ nanoparticles dispersed in a multiblock copolymer. J Appl Phys. 2006;99:084307.

9. Rafi MM, Ahmed KSZ, Nazeer KP, D. Siva KumarM. Thamilselvan. Synthesis, characterization and magnetic properties of hematite $\left(\boldsymbol{\alpha}-\mathrm{Fe}_{2} \mathrm{O}_{3}\right)$ nanoparticles on polysaccharide templates and their antibacterial activity. Appl Nanosci. 2015;5(4):515-520.

10. Baker C, Shaha S, Hasanain SK. Magnetic behavior of iron and ironoxide nanoparticle / polymer composites. J Magn Magn Mater. 2004;280(2-3):412-418.

11. Novakova AA, Lanchinskaya VY, Volkova AV, Gendler TS, Moskvina MA, Zezin SB, et al. Magnetic properties of polymer nanocomposites containing iron oxide nanoparticles. J Magn Magn Mater. 2003;258:354-357.

12. Erkartal M, Aslan A, Erkilic U, Seyma Dadi, Ozgur Yazaydin, Hakan Usta, et al. Anhydrous proton conducting poly (vinyl alcohol) (PVA) / poly(2-acrylamido-2-methylpropane sulfonic acid) (PAMPS) /1.2.4-triazole composite membrane. Int J Hydrogen Energy. 2016;41(26):11321-11330.

13. Erkartal M, Usta H, Citir M, Unal Sen. Proton conducting poly(vinyl alcohol) (PVA) / poly(2-acrylamido-2-methylpropane sulfonic acid) (PAMPS) / zeoliticimidazolate framework (ZIF) ternary composite membrane. J Membr Sci. 2016;499:156-163.

14. Halima NB. Poly(vinyl alcohol): review of its promising applications and insights into biodegradation. RSC Adv. 2016;46:39823-39832.

15. Florjańczyk Z, Zygadło-Monikowska E, Wielgus-Barry E, Kuźwaet K, Paśniewski J. Proton conducting electrolytes based on poly(2acrylamido-2-methyl-1-propanesulfonic acid). Electrochim Acta. 2003;48(14-16):2201-2206.

16. Guo Z, Zhang D, Wei S, Zhe Wang, Amar B. Karki, Yuehao Li, et al. Effects of iron oxide nano-particles on polyvinyl alcohol: interfacial layer and bulk nanocomposites thin film. J Nanopart Res. 2010;12(7):2415-2422.

17. Farahmandjou M,Soflaee F. Synthesis of Iron Oxide Nano-particles using Borohydride Reduction. Int J Bio-Inorg Hybr Nano mater. 2014;3(4):203-206.

18. Hyojin $\mathrm{K}$, Dowon S. Influence of water saturation on fracture toughness in woven natural fiber reinforced composites. Adv Composite Mater. 2007;16(2):83-94.

19. Gonga C, Zheng X, Liu H, Wang G, Cheng F, Zheng G, et al. A new strategy for designing high-performance sulfonated poly(ether ether ketone) polymer electrolyte membranes using inorganic proton conductor-functionalized carbon nanotubes. J Power Sources. 2016;325:453-464.

20. Kaushik A, Khan R, Solanki PR, Pandey P, Alam J, Ahmadet S, et al. Iron oxide nanoparticles-chitosan composite based glucose biosensor. Biosens Bioelectron. 2008;24(4):676-683. 
21. Sharma G, Jeevanandam P. Synthesis of self-assembled prismatic iron oxide nanoparticles by a novel thermal decomposition route. RSC Adv. 2013;3(1):189-200.

22. Masthoff IC, Kraken M, Menzel D, LitterstG FJ, Garnweitner G. Study of the growth of hydrophilic iron oxide nanoparticles obtained via the non-aqueous sol-gel method.J Sol-Gel Sci Technol. 2016;77:553564 .
23. Gupta AK, Gupta M. Synthesis and surface engineering of iron oxide nanoparticles for biomedical applications. Biomaterials. 2005;26:3995-4021.

24. Laurent S, Forge D, Port M, Roch A, Robic C, Robert N, et al. Magnetic Iron Oxide Nanoparticles: Synthesis, Stabilization, Vectorization, Physicochemical Characterizations and Biological Applications. Chem Rev. 2008;108:2064-2110. 